\title{
Second language vocabulary acquisition: Male vs female learners and the role of words associated with emotion
}

Schuetze, Ulf $\square$

University of Victoria, Canada (ulfs@uvic.ca)

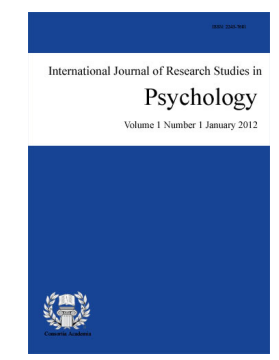

Accepted: 18 July 2016 Online ISSN: 2243-769X

OPEN ACCESS

\section{Abstract}

In order to make vocabulary learning efficient, one line of research is to investigate what role spacing techniques play when words are processed to memory (Nation, 2001; 2009). In this context, the role of neurotransmitters, that are part of the neurophysiological process of rehearsing and recalling words, has not been investigated. One question is if female students, who have higher levels of estrogen than male students, that stimulate the production of the neurotransmitter serotonin, have a natural advantage processing words using spacing techniques. Another question is if words associated with emotion are processed faster, as the neurotransmitter serotonin is linked to happiness and the neurotransmitter dopamine is linked to pleasure. This article reports on a study that was carried out in North America with learners of German (beginners' level). It investigated if recall rates differ between female and male students using spacing techniques, in particular in regards to words associated with emotion. Results (using inferential statistics) showed that female students recalled words more successfully than male students if the words had been rehearsed five times. However, the effect was not robust, in particular in regards to emotional words. Furthermore, the rate of forgetting was significant for both, female and male students.

Keywords: second language acquisition; vocabulary learning; memory; emotion; gender 


\section{Second language vocabulary acquisition: Male vs female learners and the role of words associated with emotion}

\section{Introduction}

Among other things, one challenge when learning a second language (L2) is to acquire many new words in a relatively short period of time. A question often asked by learners is how to achieve that goal. One line of research in regards to vocabulary acquisition has investigated how words are processed to memory and what role spacing techniques play in this context. Initially, most of these studies came from cognitive psychologists who carried out experiments with native speakers who were asked to learn uncommon words of their first language (L1), or non-words or digits (for an overview, see Balota, Duchek, \& Logan, 2007). These studies tested short-term gains. They showed that repeating words several times using a spacing technique where there is a pause in between each encounter lead to high recall rates. For second language learners, however, the goal is to recall a word from long-term memory, that is, weeks and month after the word has been acquired. Studies with second language learners have confirmed that an expanded interval - for example a word is repeated after one day, two days, three days, six days - in tendency leads to higher recall rates on short-term gains than a uniform interval - for example the word is repeated every two days. However, studies have also shown that on long-term memory, when a test is carried out several weeks later, recall rates are higher when the uniform interval was used during rehearsal (Schuetze \& Weimer-Stuckmann, 2011; Schuetze, 2015). What has not been investigated yet is to analyze the role neurotransmitters play in this context. The foundation for this argument comes from studies in neurophysiology that explain the bio-chemical process of memory formation (Kandel, 2006). When processing information, neurotransmitters such as serotonin, dopamine and acetylcholine, that are all associated with emotion, play a key role. Therefore, a hypothesis is that words associated with emotion might be fast tracked. Furthermore, it is known that estrogen stimulates serotonin. A question then is, if female students, who naturally have higher levels of estrogen than male students, are more successful processing words to memory, in particular, if these are emotional words.

\section{Context}

It is surprising how little students remember at the end of a two-year university language program when it comes to vocabulary (Milton, 2009). Naturally, we must ask ourselves as instructors what we expect students to do with the vocabulary. Ideally, as Cook and Singleton (2014) point out, students do not just recognize words in another language but can actively produce them in a meaningful sentence. Nation (2001) explains this further. In his model of what it means to know a word, Nation distinguishes between form (spoken/written) and meaning (concepts/relationships). The questions he raises are how form and meaning interact, what parts of a word are needed in order to recognize or produce a word and what other words the word is associated with. Furthermore, aspects of how words are used in multiple contexts play a role: the grammatical patterns of a word, collocations, as well as when and how often we encounter or use a particular word.

While the form to meaning relationship needs to be established right from the start when acquiring new words, the other aspects of form, meaning, and multiple usages should not be neglected. Unfortunately, this is how most textbooks operate. Analyzing the vocabulary presented and practiced in four German textbooks published in North America and used for first-year German courses at college or university in the United States and Canada, Neary-Sundquist (2015) found that these textbooks focus on the form to meaning relationship almost exclusively. Another problem with textbooks or online programs is that they do not recycle words very well. For example, if they are introduced in one chapter, they are not necessarily used again in subsequent chapters (Tschichold, 2012). Analyzing a French textbook for learners of English, Tschichold found that many words are presented in an unstructured format and it is left up to the learner and/or teacher to make sense of it all. 
Similarly, López-Jiménez (2010) analyzed twenty-four textbooks for teaching Spanish and English and pointed out that in English textbooks, vocabulary is often recycled too much and in Spanish textbooks, too little. In general, considerations of repetition, frequency or cognitive load are neglected.

Furthermore, when it comes to vocabulary learning, we need to look at the approach. In general, a distinction is being made between incidental and rote learning (Cook \& Singleton, 2014). Incidental learning assumes that students learn words by reading authentic texts because these texts provide a rich source of a language's vocabulary (Hulstijn, 1992). Husltijn acknowledges, though, that this method can be ineffective as the number of words learners acquire by reading is relatively small. This has also been argued by van Zeeland and Schmitt (2013), as well as by Barcroft (2009). Rote learning, also called intentional learning, isolates words. It is efficient because repetition fosters the so-called subvocal rehearsal process (Ellis, 1995). Very popular to learn words using this method is with the assistance of flashcards. Flashcards have the advantage of providing information using several modalities which caters to different learning styles (Kim \& Gilman, 2008; Oxford, 2003). Zimmermann (2009) recommended that when using flashcards on paper, a computer or a smart phone, one should add information every time a word is used but cautions at the same time not to write too much information on the cards because this could cause confusion. As to what type of information should be on the card, Zimmerman recommended the meaning of the word as well as examples of how that word is used. We also know that pictures are helpful as they stimulate the senses to process non-linguistic information. Overall, the learner should have the option to decide how much of that information s/he wants to see at the same time or in succession (Nation, 2009). Furthermore, learners need to be given the opportunity to produce a word (Webb, 2005). What is sometimes forgotten in this debate between incidental and rote learning is the level of proficiency of the learner. In order to learn words from authentic texts some knowledge of the language learned is essential. Therefore, rote learning is often a preferred method at the beginner's level whereas incidental learning is used with intermediate or advanced learners.

The effectiveness of rote learning is linked to how words are processed to memory: Linguistic information in form of lexemes and phonemes as well as non-linguistic information from the senses is transmitted to the hippocampus where the record of a word is created (for an overview, see Tranel \& Damasio, 2002). Several faculties of the brain are involved: the phonological loop, Broca's and Wernicke's area, the Amygdala and several cortices, as well as the hippocampus itself. First, a word that is encountered needs to be rehearsed to identify its phonemes and match them to a lexeme by comparing it to the repertoire of phonemes and lexemes and the possible combinations that are available (Baddeley, 2007). Second, sensory information, for example visual or auditory or olfactory information, are fed via the enthornial and perirhinal cortices to the hippocampus (Gluck \& Myers, 2001). The hippocampus collects all the linguistic and non-linguistic information and creates a record of the word (Milner, Squire, \& Kandel, 1998). Furthermore, the Amygdala that plays a key role in processing emotions, might tag a word in order to fast-track it (Amaral, Prince, Pitkanen, \& Carmichael, 1992). If a record of a word is created, it is stored in the non-mesial region deep down in the brain. The record itself is stored in form of a synapse and the formation of the synapse is dependent on neurotransmitters such as serotonin as well as dopamine and acetylcholine (Kandel, 2006). In essence, these neurotransmitters cause a stimulation of a neuron that depending on the strength and duration leads to a temporary signal that is transmitted to another neuron or a permanent one. If it is to be permanent, an actual synapse is being built by one neuron attaching itself to another neuron. This is important for long-term memory as the information can be accessed permanently. When a word is recalled from long-term memory, the records of several words are recalled as well as phonemes. These are rehearsed in Broca's area of speech production where a lexeme is matched to its phonemes in order to be articulated. The record includes the non-linguistic information that was transmitted via the senses. It assists in the matching process. If much sensual information is recorded with a word, the activation is heightened, a higher dose of a neurotransmitter released and a strong record created. A strong record can be recalled fast as it stands out from the record of other words.

Consequently, in this context, not only the type of interval plays a role but how often a word needs to be repeated during rehearsal (Schuetze, 2015; Nation, 2001; Schmitt, 2010). Naturally the number of repetitions 
depends on the learning situation, for example, if the word of the target language is acquired in a context where the target language is pre-dominantly spoken or not, as well as individual factors such as the background of the learner in regards to age; knowledge of other languages; motivation and the proficiency level (Singleton, 1995 , 2007).

In the context of learning German at a West Coast university in North America, previous studies having learners repeat words five times over a time period of ten days have shown that on short-term gains, recall rates are higher when the expanded interval was used during rehearsal (Schuetze \& Weimer-Stuckmann, 2011; Schuetze, 2015). This confirmed studies carried out in cognitive psychology (Balota et al., 2007). Interestingly, the studies carried out by Schuetze (2015) also showed that the uniform interval was more robust, that is, the rate of forgetting using the uniform interval was lower compared to the expanded interval when learners where tested on long-term memory several weeks after they rehearsed the words.

It has to be kept in mind that the number five is not a magical number but simply worked in that particular learning environment. Furthermore, the number of repetitions also depends on the words. Cognates, for example, need less repetition because they are easily identified and processed. The fact that neurotransmitters such as serotonin, dopamine and acetylcholine play a key role when processing words raises the question if words that are associated with emotions are also easily processed and therefore need less repetition because all of these neurotransmitters are linked to emotion. Serotonin is associated with happiness, dopamine with pleasure and acetylcholine with arousal (Aleman, 2013). A study by Altarriba, Bauer, and Benvenuto (1999) investigated monolingual speakers of English repertoire of concrete, abstract, and emotional words. The speakers were given a word and had to write down the first word that came to mind that was meaningfully related to the given word. All in all, 55 speakers were given 352 words each: 100 concrete words (for example "car"), 154 abstract words (for example "wisdom"), and 98 emotional words (for example "joy"). Results showed that the words written down for the emotional words produced the highest number of different associates. This supports the argument that words associated with emotions might be processed faster.

If words associated with emotions need less repetition, language instructors could group each textbook's chapter vocabulary into three categories: Regular words (several repetitions necessary), words linked to emotions (few repetitions necessary), and cognates (no repetition necessary). As students who learn a language for the first time need to acquire many new words in a short period of time, it would be helpful for them to have this type of breakdown of a textbook's chapter vocabulary. Another question is if female students are more successful processing words associated with emotion compared to male students because they have higher levels of estrogen that in turn is a stimulator for the neurotransmitter serotonin.

In order to answer these questions, a series of experiments with undergraduate students enrolled in a course called 'Beginning German I' was designed testing to investigate the following research questions:

$>\quad$ Is there a difference between female and male learners recalling words successfully in the short-term and/or on long-term memory? Is this linked to emotional words?

$>$ Are words associated with emotion fast-tracked, that is, do they only need few repetitions?

\section{Method}

The experiments were carried out in the fall of 2014 and 2015 with students enrolled in three sections (2014) and four sections (2015) of a course called 'Beginning German I' at a West Coast University in North America. It investigated the acquisition of twenty-four words, twelve words associated with emotion and twelve words that are not commonly associated with emotion. In 2014, students in section one practiced the words once, students in section two three times, and students in section three five times. In order to fit the schedule, the expanded interval was used. In 2015, students practiced the words five times while in two sections the expanded and in the other two sections the uniform interval was used. Both studies, in 2014 and 2015, consisting of several 
Second language vocabulary acquisition: Male vs female learners and the role of words associated with emotion experiments each, were approved by the university's Ethics board and funded with an internal research grant. The procedure, material used, and setting of the studies was similar to ensure reliability of the results.

\subsection{Participants}

Students were undergraduates age seventeen to twenty-four. Students taking 'Beginning German I' are supposed to have no or very little knowledge of German. However, in order to ensure that the students participating in the experiments were indeed beginning learners, students had to fill out a background questionnaire identifying previous knowledge of German, previous instruction in German, German heritage, proficiency in other languages, and provided social data on faculty, major, and years of study. The questionnaire was used to exclude students from the study who did not fit the profile required for the experiments.

In 2014, in group I (section one: one encounter), twenty-four students (twelve female/twelve male) who did fit the profile participated in the experiments from start to finish. In group II (section two: three encounters), twenty-seven students (fifteen female/twelve male) did and in group III (section three: five encounters) twenty-five students (twelve female/thirteen male). In 2015, in the two sections using the expanded interval fifty students (twenty-four female/ twenty-six male) participated from start to finish; in the two sections using the uniform interval forty-eight (twenty-five female/twenty-three male students) did.

\subsection{Material}

Of the twelve words associated with emotion selected for the experiments six had a positive association such as "Liebe" [love], "freuen" [to rejoice], "glücklich" [happy] and six a negative association such as "Verrat" [betryal], "lügen" [to lie], "traurig" [sad]. They were broken down into four nouns, four verbs and four adjectives with two positive and two negative associated words in each grammatical category. Word selection was based on frequency using Jones and Tschirner's dictionary (2006) as well as on the textbook used for 'Beginning German I.' Only words that were not uncommon, as well as were not occurring in the first five chapters of that textbook, were selected to ensure that hearing and seeing the words with the PowerPoint slides was the only contact to the words participants had. The other twelve words also consisted of four nouns, four verbs and four adjectives. Therefore a total of eight nouns, eight verbs, and eight adjectives were tested. All words were two to three syllables in length.

\subsection{Procedure}

For each word a PowerPoint slide was created using the same font and same background color for all slides. In the middle of each slide was an image representing the word. On each slide the English word was presented on the left side of the image. After two seconds the German equivalent word was presented on the right side and appeared for six seconds while the English word remained on the screen. The German word that appeared was spoken. Each slide was shown for eight seconds. This method is a standard procedure in rote vocabulary learning (Roediger \& Karpicke, 2010). The reason to include sound was to reflect the situation of how a learner often encounters a word in another language. Participants were asked to copy down the German word they saw and heard on a piece of paper. This was done as they had to write down the German words in the tests that followed so the activity of writing was practiced. Each PowerPoint was presented in the first five minutes of class time. Those students not participating in the experiments were asked to wait outside the classroom until regular class began. Once the PowerPoint was shown and participants had copied down all words on a piece of paper, all paper was collected by the research assistant. Each time the order of the words presented was different to avoid testing effects; that is, the order of words primes the next word.

\subsection{Tests}

Two retention tests were carried out: one test at the end of class of the last practice approximately 30 minutes after the PowerPoint had been shown for the last time (test one), and one test four weeks after the last 
practice had occurred. In each test, all twenty-four words were tested. In all tests, the English word was given and participants had to write down the German word. In each test, the order of the words in the test was different.

\subsection{Limitations}

It was possible that students did have contact with the words tested outside the study by for example surfing for things German on the internet. However, based on the experience of other studies carried out on vocabulary acquisition at the beginners' level, the probability of such a situation was quite low due to the busy schedule of students taking five to six courses per term. Furthermore, the probability was the same for all groups.

\section{Results}

The success of recalling words was measured using inferential statistics. The 2014 study showed that overall participants who encountered all twenty-four words five times recalled significantly more words in all three tests than participants who saw the PowerPoint three times than participants who saw the words once. An analysis using ANOVA showed these differences were statistically significant with all p values below .05 (see Table 1). On long-term retention (test 3), recall rates were close to fifty percent for group III, a bit over thirty percent for group II, and ten percent for group I. These rates confirmed results of previous experiments (Schuetze \& Weimer-Stuckmann, 2011; Schuetze, 2015).

Table 1

Overall recall rates all words 2014 study

\begin{tabular}{llllllll}
\hline & $\begin{array}{c}\text { 1 encounter } \\
\text { Mean }\end{array}$ & SD & Mencounters & \multicolumn{2}{c}{5 encounters } \\
& Mean & SD & Mean & SD & $p$ \\
\hline Test 1 & 8.53 & 3.75 & 13.29 & 5.77 & 15.99 & 8.08 & .000 \\
Test 2 & 2.02 & 1.44 & 7.88 & 5.30 & 11.97 & 4.41 & .002 \\
\hline
\end{tabular}

In all tests, the number of participants was 24 in group one (one encounter: 12 female and 12 male), 27 in group II (three encounters: 15 female and 12 male) and 25 in group III (five encounters: 12 female and 13 male). The Mean refers to the average score of participants. 24 words were tested so the maximum score was 24 .

In the 2014 and 2015 study, female students recalled more words than male students, if they rehearsed words five times (see Table 2) in five of the six tests. The only statistically significant result was the 2015 group that used an expanded interval. In that group, female students recalled significantly more words than male students on the immediate post-test. The effect size for that difference was calculated (using Means and Standard Deviations for independent groups) at 0.2163 which is considered a small effect. Interestingly, the 2014 study showed that when rehearsing words once or three times, male students recalled more words than female students in the immediate post-test. However, those differences were not significant. Furthermore, those male students recalled fewer words than the female students on the four-week delayed post-test.

In 2014, the number of participants was 24 in group one (one encounter: 12 female and 12 male), 27 in group II (three encounters: 15 female and 12 male) and 25 in group III (five encounters: 12 female and 13 male). In 2015 , the number of participants in the expanded group was 50 (24 female and 26 male participants) and in the uniform group 48 ( 25 female and 23 male). In 2014 and 2015, 24 words were tested.

A further statistical analysis using ANOVA showed that in both, the 2014 and 2015 study, the differences between test 1 and test 2 for both, female and male students, were significant when rehearsing the words five times. All six p values were p .000: female students 2014 test 1 Mean 16.66, SD 7.42 vs test 2 Mean 12.16, SD 4.79, as well as 2015 test 1 expanded Mean 16.30, SD 3.34 vs test 2 Mean 11.86, SD 4.05 as well as test 1 uniform Mean 13.28, SD 4.41 vs test 2 Mean 11.01, SD 4.96; male students 2014 test 1 Mean 14.65, SD 8.24 vs test 2 Mean 11.83, SD 3.63, as well as 2015 expanded test 1 Mean 14.65, SD 4.07 vs test 2 Mean 10.34, SD 3.23, 
Second language vocabulary acquisition: Male vs female learners and the role of words associated with emotion as well as 2015 uniform test 1 Mean 13.44, SD 3.79 vs test 2 Mean 10.78, SD 4.84. These numbers indicate that female and male students alike forgot a significant number of words within the time span of four weeks.

Table 2

Female vs Male overall recall rates

\begin{tabular}{|c|c|c|c|c|c|}
\hline & $\begin{array}{l}\text { Female } \\
\text { Mean }\end{array}$ & SD & $\begin{array}{l}\text { Male } \\
\text { Mean }\end{array}$ & SD & $p$ \\
\hline \multicolumn{6}{|l|}{ Test 12014} \\
\hline 1 encounter & 4.16 & 2.83 & 4.66 & 3.01 & .651 \\
\hline 3 encounters & 13.16 & 5.96 & 13.50 & 6.67 & .743 \\
\hline 5 encounters & 16.66 & 7.42 & 15.66 & 8.24 & .102 \\
\hline \multicolumn{6}{|l|}{ Test 22014} \\
\hline 1 encounter & 2.20 & 1.83 & 1.83 & .75 & .595 \\
\hline 3 encounters & 8.05 & 3.61 & 7.61 & 3.70 & .730 \\
\hline 5 encounters & 12.16 & 4.79 & 11.83 & 3.63 & .490 \\
\hline \multicolumn{6}{|l|}{ Test 12015} \\
\hline 5 encounters (expanded) & 16.30 & 3.34 & 14.65 & 4.07 & .037 \\
\hline 5 encounters (uniform) & 13.28 & 4.41 & 13.44 & 3.79 & .605 \\
\hline \multicolumn{6}{|l|}{ Test 22015} \\
\hline 5 encounters (expanded) & 11.86 & 4.05 & 10.34 & 3.23 & .151 \\
\hline 5 encounters (uniform) & 11.01 & 4.96 & 10.78 & 4.84 & .578 \\
\hline
\end{tabular}

Table 3 shows the difference between words associated with emotion and words not associated with emotion (female and male students grouped together) using a paired samples t-test. The only statistical difference was when participants practiced words five times with the expanded interval in the 2015 study and had to recall them on test 2. In all other tests participants who had rehearsed words five times recalled more emotional than non-emotional words as well but differences were minimal, although differences in the delayed post-tests were higher than in the immediate post-tests.

Table 3

Words of all groups

\begin{tabular}{lccccc}
\hline & \multicolumn{2}{c}{ Emotional words } & \multicolumn{2}{c}{ Non emotional words } & \\
& Mean & SD & Mean & SD & $p$ \\
\hline 2014 - 1 encounter: & & & & & \\
Test 1 & 2.43 & 1.56 & 2.00 & 1.09 & .193 \\
Test 2 & 1.66 & 1.36 & 0.66 & 1.00 & .229 \\
\hline 2014 - 3 encounters: & & & & & \\
Test 1 & 7.16 & 2.63 & 6.53 & 3.23 & .367 \\
Test 2 & 4.33 & 2.08 & 3.70 & 1.76 & .303 \\
\hline 2014 - 5 encounters: & & & & & \\
Test 1 & 8.18 & 2.98 & 7.49 & 3.01 & .465 \\
Test 2 & 6.33 & 2.08 & 5.61 & 2.76 & .071 \\
\hline 2015 expanded - 5 encounters: & & & & \\
Test 1 & 7.65 & 2.23 & 7.40 & 2.18 & .371 \\
Test 2 & 5.96 & 1.90 & 5.06 & 2.23 & .032 \\
\hline 2015 uniform - 5 encounters: & & & & \\
Test 1 & 6.85 & 2.01 & 6.65 & 2.10 & .570 \\
Test 2 & 5.41 & 2.30 & 5.06 & 2.07 & .182 \\
\hline
\end{tabular}

In 2014, the number of participants was 24 in group one (one encounter: 12 female and 12 male), 27 in group II (three encounters: 15 female and 12 male) and 25 in group III (five encounters: 12 female and 13 male). In 2015, the number of participants in the expanded group was 50 (24 female and 26 male participants) and in the uniform group 48 (25 female and 23 male). In 2014 and 2015, 24 words were tested, equally divided into 12 associated with emotion and 12 words not associated with emotion. 
Schuetze, U.

A further analysis of the performance of the female students (see Table 4) as well as the male students (see Table 5) using paired sample t-tests showed that in the 2015 study female students recalled significantly more emotional words in test 2 than non-emotional words if they had used the expanded interval. In the 2014 study, those particular results were not statistically significantly different.

Table 4

Words of all groups Female students

\begin{tabular}{lcclcc}
\hline & \multicolumn{2}{c}{ Emotional words } & \multicolumn{2}{c}{ Non emotional words } & \\
& Mean & SD & Mean & SD & $p$ \\
\hline 2014 - 5 encounter: & & & & & \\
Test 1 & 8.35 & 1.42 & 7.91 & 1.83 & .339 \\
Test 2 & 6.91 & 1.72 & 6.16 & 2.12 & .241 \\
\hline 2015 expanded - 5 encounter: & & & & \\
Test 1 & 8.21 & 1.85 & 8.17 & 1.92 & .911 \\
Test 2 & 6.82 & 1.80 & 5.69 & 2.43 & .006 \\
\hline 2015 uniform - 5 encounter: & & & & \\
Test 1 & 7.03 & 2.05 & 6.87 & 1.69 & .794 \\
Test 2 & 5.82 & 2.09 & 5.40 & 2.23 & .276 \\
\hline
\end{tabular}

In 2014, the number of participants was 25 in group III (five encounters: 12 female and 13 male). In 2015, the number of participants in the expanded group was 50 ( 24 female and 26 male participants) and in the uniform group 48 (25 female and 23 male). In 2014 and 2015, 24 words were tested, equally divided into 12 associated with emotion and 12 words not associated with emotion.

Table 5

Words of all groups Male students

\begin{tabular}{lcclcc}
\hline & \multicolumn{2}{l}{ Emotional words } & \multicolumn{2}{l}{ Non emotional words } & \\
& Mean & SD & Mean & SD & $p$ \\
\hline 2014 - 5 encounter: & & & & & \\
Test 1 & 7.41 & 2.23 & 6.91 & 2.06 & .305 \\
Test 2 & 4.83 & 1.58 & 4.58 & 2.35 & .721 \\
\hline 2015 - 5 encounter: & & & & & \\
Test 1 & 7.16 & 2.49 & 6.62 & 2.16 & .202 \\
Test 2 & 5.91 & 1.93 & 5.45 & 1.86 & .201 \\
\hline 2015 uniform - 5 encounter: & & & & \\
Test 1 & 6.57 & 1.76 & 6.29 & 1.88 & .533 \\
Test 2 & 5.20 & 1.99 & 4.87 & 2.06 & \\
\hline
\end{tabular}

In 2014, the number of participants was 25 in group III (five encounters: 12 female and 13 male). In 2015, the number of participants in the expanded group was 50 ( 24 female and 26 male participants) and in the uniform group 48 (25 female and 23 male). In 2014 and 2015, 24 words were tested, equally divided into 12 associated with emotion and 12 words not associated with emotion.

\section{Discussion}

Overall, it should be noted that recall rates on long-term retention were in line with Milton's (2009) observation that many words are forgotten soon after they had been encountered. The results showed that with an increasing number of practices the retention rate went up. This was consistent across all tests. This comes at no surprise as previous studies (Schuetze, 2015) have shown that the number of repetitions play a role when processing words to short- as well as to long-term memory.

The first research question was if female learners recall more words than male learners. They might if there is enough stimulation. When words were processed five times, recall rates for female students were higher than 
those of male students in both studies five out of six times (three immediate and three delayed post-tests). However, only once, on the immediate post-test using the expanded interval, differences were statistically significant. This indicates that overall the stimulation by estrogen to the neurotransmitter serotonin did not make a significant difference in lexical processing. An explanation might be that the stimulation was not sufficient to make such a difference.

The results confirmed that both, female and male students, recall more words when the expanded interval is used on short-term gains but then forget more words when tested weeks later relatively to when the uniform interval is used. In previous studies (Schuetze \& Weimer-Stuckmann, 2011; Schuetze, 2015), the effect that the uniform group had higher recall rates in the long-run was shown in delayed post-tests of eight weeks or more. Furthermore, the results showed that the rate of forgetting was similar for female and male students: differences between the immediate and the delayed post-test were statistically significant for both, male and female students.

The second part of the first research question was, if recall rates by female students are particularly high when processing words associated with emotion. There was only one significant difference when female students recalled emotional vs non-emotional words which was in the 2015 expanded group who rehearsed the words five times on the delayed post-test. In indicates that that particular group forgot fewer emotional than non-emotional words within the time span of four weeks. The other groups who rehearsed the words five times also showed that effect but differences were not statistically significant.

The second research question was if words associated with emotion were fast-tracked. The short answer is no. Although all tests showed that participants did recall more words associated with emotion than words not associated with emotion, differences were minimal. A possible explanation is that the sensory information that is fed through the cortices to the Hippocampus when processing words to long-term memory (Amaral et al., 1992; Gluck \& Meyers, 2011; Milner et al., 1998) was not heightened enough to create a higher dose of a neurotransmitter. However, there was one interesting result. The 2015 group (male and female students grouped together) that used the expanded interval five times recalled significantly more emotional than non-emotional words on the delayed post-tests. This was the same group where female students recalled significantly more words than male students on the immediate post-tests. It might be an indication that for female students higher estrogen levels paired with the heightened activation of emotional words can lead to higher recall rates. However, more tests are needed to validate or reject this finding. The other tests (with fewer repetitions and/or using the uniform interval) did not show this effect. Therefore the effect is not robust.

What are the implications of this research for the classroom? Results confirmed previous studies that at the beginner's level rote learning is an efficient method to acquire many words in a short period of time. In the context of acquiring a second language at a college or university in North America five rehearsals are necessary to attain high recall rates. Based on the experiments carried out in this study, words associated with emotion need to be repeated as much as words not associated with emotion. In order to produce higher levels of neurotransmitters such as serotonin as well as dopamine and acetylcholine (Kandel, 2006) more stimulation is needed than is provided by simply repeating them.

In any beginner's language course, students would benefit if instructors explain to them how to study vocabulary. The explanations should include the role intervals play, the fact that all words (except cognates) need to be repeated, that rote learning works well at the beginner's level but at a more advanced level different methods should be tried (for example reading longer texts). Something that works at all levels is to create situations that stimulate the senses. For example, learning words related to food, one can take students to a restaurant or organize an in-class breakfast. Unfortunately, that is not efficient. However, it increases the amount of neurotransmitters.

If words are repeated five times, female students might have a slight advantage over male students when learning emotional words that might be caused by the higher levels of estrogen that in turn stimulate serotonin. The effect was not robust, though. More studies in this area are needed to explore this issue further by focusing 
Schuetze, U.

on experiments with five rehearsals, increase the number of words tested, as well as the number of female and male students.

\section{Reference}

Aleman, A. (2013). Wenn das Gehirn älter wird. [When the brain ages]. München: Beck.

Altarriba, J., Bauer, L., \& Benvenuto, C. (1999). Concreteness, context-availability, and imageability ratings and word associations for abstract, concrete, and emotion words. Behavior Research Methods, Instruments, and Computers, 31, 578-602. http://dx.doi.org/10.3758/BF03200738

Amaral, D., Prince, J., Pitkanen, A., \& Carmichael, S.T. (1992). Anatomical organization of the primate amygdaloid complex. In J. Aggleton (Ed.), The amygdala: Neurobiological aspects of emotion, memory, and mental dysfunction (pp. 1-66). New York: Wiley-Liss.

Baddeley, A. (2007). Working memory, thought, and action. Oxford: Oxford University Press. http://dx.doi.org/10.1093/acprof:oso/9780198528012.001.0001

Balota, D., Duchek, J., \& Logan, J. (2007). Is expanded retrieval practice a superior form of spaced retrieval? A critical review of the extant literature. In J. Nairne (Ed.), The foundations of remembering (pp. 83-105). London: Psychology Press.

Barcroft, J. (2009). Effects of synonym generation on incidental and intentional vocabulary learning during second language reading. TESOL Quarterly, 43, 79-103. http://dx.doi.org/10.1002/j.1545-7249.2009.tb00228.x

Cook, V., \& Singleton, D. (2014). Key topics in second language acquisition. Bristol: Multilingual Matters.

Ellis, N. (1995). Vocabulary acquisition: Psychological perspectives. The Language Teacher, 19(2), 12-16.

Gluck, M., \& Myers, C. (2001). Gateway to memory: An introduction to neural network modeling of the hippocampus in learning and memory. Cambridge, MA: MIT Press.

Hulstijn, J. (1992). Retention of inferred and given word meanings: Experiments in incidental vocabulary learning. In P. Arnaud \& J. Béjoint (Eds.), Vocabulary and applied linguistics (pp. 113-125). Houndmills: Macmillan. http://dx.doi.org/10.1007/978-1-349-12396-4_11

Jones, L., \& Plass, J. (2002). Supporting listening comprehension and vocabulary acquisition in French with multimedia annotations. Modern Language Journal, 86(4), 546-561. http://dx.doi.org/10.1111/1540-4781.00160

Jones, R., \& Tschirner, E. (2006). A frequency dictionary of German. London: Routledge.

Kandel, E. (2006). In search of memory. The emergence of a new science of mind. New York: W.W. Norton \& Company.

Kim, D., \& Gilman, D.A. (2008). Effects of text, audio, and graphic aids in multimedia instruction for vocabulary learning. Educational Technology \& Society, 11(3), 114-126.

López-Jiménez, M.D. (2010). The Treatment of Lexical Aspects in Commercial Textbooks for L2 Teaching and Learning. In R. Chacón-Beltrán, C. Abello-Contesse, \& M. del Mar Torreblance-López (Eds.), Insights into non-native vocabulary teaching and learning (pp. 156-174). Bristol: Multilingual Matters.

Milner, B., Squire, L., \& Kandel, E. (1998). Cognitive neuroscience and the study of memory. Neuron, 20(3), 445-468. http://dx.doi.org/10.1016/S0896-6273(00)80987-3

Milton, J. (2009). Measuring second language vocabulary acquisition. Bristol: Multilingual Matters.

Nation, I.S.P. (2001). Learning vocabulary in another language. Cambridge: Cambridge University Press. http://dx.doi.org/10.1017/CBO9781139524759

Nation, I.S.P. (2009). Teaching vocabulary. Strategies and techniques. Boston: Heinle.

Neary-Sundquist, C. (2015). Aspects of vocabulary knowledge in German textbooks. Foreign Language Annals, 48(1), 68-81. http://dx.doi.org/10.1111/flan.12126

Oxford, R. (2003). Language learning styles and strategies: Concepts and relationships. International Review of Applied Linguistics in Language Teaching, 41, 271-278. http://dx.doi.org/10.1515/iral.2003.012

Roediger, H., \& Karpicke, J. (2010). Intricacies of spaced retrieval: A resolution. In A. Benjamin (Ed.), Successful remembering and successful forgetting: Essays in honor of Robert A. Bjork (pp. 1-36). New 
York: Psychology Press.

Schmitt, N. (2010). Researching vocabulary. Basingstoke: Palgrave Macmillan. http://dx.doi.org/10.1057/9780230293977

Schuetze, U. (2015). Spacing techniques in second language vocabulary acquisition: Short-term gains vs long term memory. Language Teaching Research, 19(1), 28-42. http://dx.doi.org/10.1177/1362168814541726

Schuetze, U., \& Weimer-Stuckmann, G. (2011). Retention in SLA lexical processing. CALICO Journal, 28(2), 460-472. http://dx.doi.org/10.11139/cj.28.2.460-472

Singleton, D. (1995). Introduction: a critical look at the critical period hypothesis in second language acquisition research. In D. Singleton \& Z. Lengyel (Eds.), The age factor in second language acquisition: a critical look at the critical period hypothesis (pp.1-29). Clevedon: Multilingual Matters. http://dx.doi.org/10.1097/00013614-199503000-00002

Singleton, D. (2007). The critical period hypothesis: Some problems. Interlingüîstica, 17, 48-56.

Tranel, D., \& Damasio, A. (2002). Neurobiological foundations of human memory. In A. Baddeley, M. Koppelman, \& B. Wilson (Eds.), Handbook of memory disorders ( ${ }^{\text {nd }}$ ed., pp. 17-56). Chichester: Wiley.

Tschichold, C. (2012). French vocabulary in Encore Tricolore: Do pupils have a chance? The Language Learning Journal, 40(1), 7-19. http://dx.doi.org/10.1080/09571736.2012.658219

van Zeeland, H., \& Schmitt, N. (2013). Incidental vocabulary acquisition through L2 listening. System, 41, 609-624. http://dx.doi.org/10.1016/j.system.2013.07.012

Webb, S. (2005). Receptive and productive vocabulary learning: The effects of reading and writing on word knowledge. Studies in Second Language Acquisition, 27, 33-52. http://dx.doi.org/10.1017/s0272263105050023

Zimmerman, C. B. (2009). Word knowledge: A vocabulary teacher's handbook. Oxford: Oxford University Press. 
Nouns associated with emotion (4)

die Liebe [the love]

die Niederlage [the defeat]

die Freiheit [the freedom]

der Verrat [the betrayal]

Verbs associated with emotion (4)

heiraten [to marry]

lügen [to lie]

weinen [to cry]

freuen [to rejoice]

Adjectives associated with emotion (4)

$\begin{array}{ll}\text { verrückt } & \text { [crazy] } \\ \text { traurig } & \text { [sad] } \\ \text { ehrlich } & \text { [honest] } \\ \text { fröhlich } & \text { [happy] }\end{array}$

Nouns not associated with emotion (4)

das Fahrrad [the bicycle]

das Büro [the office]

der Löffel [the spoon]

der Brieföffner [the letter opener]

Verbs not associated with emotion (4)

$\begin{array}{ll}\text { malen } & \text { [to paint] } \\ \text { sammeln } & \text { [to collect] } \\ \text { trocknen } & \text { [to dry] } \\ \text { drehen } & \text { [to turn] }\end{array}$

Adjectives not associated with emotion (4)

nützlich [useful]

notwendig [necessary]

selten [rare]

langsam [slow] 